\title{
TRADISI NYAWÉR PANGANTÉN SEBAGAI BAHAN AJAR BAHASAN BUDAYA SUNDA DI SMA
}

\author{
Andri Tri Sulistian, Dedi Koswara, Dingding Haerudin \\ andrietoya@gmail.com, dedi.koswara@upi.edu, dingding.haerudin@upi.edu
}

\begin{abstract}
Abstrak
Penelitian ini dilatarbelakangi oleh rendahnya perhatian dan pengetahuan masyarakat terhadap kearifan budaya lokal yang ada dalam kehidupan sehari-hari. Salah satunya adalah tradisi nyawér pangantén yang dilaksanakan dalam upacara perkawinan adat Sunda. Berdasar pada latar belakang, penelitian ini bertujuan untuk 1) mendeskripsikan struktur dan fungsi tradisi nyawér pangantén, 2) mendeskripsikan nilai etnopedagogik yang terdapat dalam tradisi nyawér pangantén, dan 3) mendeskripsikan tradisi nyawér pangantén bisa menjadi alternatif bahan ajar bahasan budaya Sunda di SMA. Metode yang digunakan yaitu deskriptif dalam penelitian kualitatif. Sumber data dalam penelitian ini yaitu mencakup data primer dan data sekunder. Data primer diperoleh dari hasil wawancara dan observasi. Data sekunder diperoleh dari telaah pustaka dan perekaman serta pendokumentasian. Penelitian ini dikaji dengan kajian struktur tradisi lisan, etnopedagogik, serta hasil bahasannya digunakan menjadi bahan ajar di SMA. Dari hasil analisis data, dapat disimpulkan bahwa tradisi nyawér pangantén mempunyai aspék teks, ko-teks, dan konteks yang sangat penting. Selain itu, dalam tradisi nyawér pangantén juga terdapat moral manusia kepada Tuhan, kepada pribadinya, kepada manusia lainnya, kepada alam, terhadap waktu, dan dalam mencapai kepuasan lahir dan batin. Serta hasil analisis dalam pembahasan tradisi nyawér pangantén dapat digunakan sebagai bahan ajar bahasan budaya Sunda di SMA.
\end{abstract}

Kata kunci: tradisi nyawer panganten, struktur, etnopedagogik, bahan ajar.

\section{NYAWÉR PANGANTÉN TRADITION AS A TEACHING-LEARNING MATERIAL OF SUNDANESE CULTURE IN SENIOR HIGH SCHOOL}

\begin{abstract}
This research is motivated by low attention and knowledge of society to local culture wisdom that exists in everyday life. One of them is nyawér pangantén tradition which is performed in a marriage ceremony of Sundanese customs. Based on the background, this study aims 1) to describe the structure and function of nyawér pangantén tradition, 2) to describe the ethnopedagogic values contained in nyawér pangantén tradition, and 3) to describe nyawér pangantén tradition that can become an alternative to Sundanese culture learning in senior high school. The method used is descriptive in qualitative research. The data sources in this study include primary data and secondary data. Primary data was obtained from the interview and observation. Secondary data was taken from literature review, records, and documentation. This study was examined by using the study of oral tradition structure, etnopedagogic. The results of the discussion used as teaching materials in senior high school. From the results of data analysis, it can be concluded that nyawér pangantén tradition has very important text aspect, co-text, and context. Moreover, in nyawér pangantén tradition there is also the moral value of man to God, to his personality, to other human beings, to nature, to time, and in achieving physical and spiritual satisfaction. In addition, the results of the analysis in the discussion of nyawér pangantén tradition can be used as a teaching material of Sundanese culture learning in senior high school.
\end{abstract}

Keywords: Nyawer Panganten Tradition, Structure, Etnopedagogic, Teaching Materials. 


\section{PENDAHULUAN}

Masyarakat adalah tempat lahirnya kebudayaan. Kebudayaan itu tidak akan lepas dari kehidupan masyarakat. Sebab kebudayaan diciptakan oleh manusia. Kebudayaan diwariskan secara turuntemurun dari suatu masyarakat kepada masyarakat selanjutnya. Maka dari itu, kebudayaan merupakan suatu warisan kekayaan dan identitas suatu masyarakat.

Budaya erat kaitannya dengan tradisi. Tradisi bisa disebut juga adat istidat. Adat istiadat yaitu sistem budaya yang mencakup nilai-nilai budaya, pandangan hidup dan cita-cita, norma-norma dan hukum, pengetahuan, serta keyakinan yang diwariskan secara turun-temurun dari satu generasi kepada generasi berikutnya (Lubis, 2011, hal. 273).

Sebagai sistem budaya, Esten (dalam Rekha, 2014, hal. 10) menyebutkan bahwa tradisi merupakan suatu sistem yang utuh dengan mencakup cara memaknai ucapan, tingkah laku, ritual, dan tindakan lainnya dari satu manusia terhadap manusia lainnya. Unsur terkecil dari sistem itu adalah simbol. Simbol ini mencakup simbol konstitutif (berbentuk kepercayaan), simbol kognitif (berbentuk ilmu pengetahuan), simbol yang berbentuk nilai moral, dan simbol ekspresif atau simbol yang berhubungan dengan rasa. Setiap masyarakat memiliki simbol khusus yang membedakan dan sekaligus menjadi ciri identitas terhadap masyarakat lainnya. Jikalau suatu masyarakat sering berinteraksi dan hidup berdampingan dengan masyarakat lain yang heterogen, tentu besar kemungkinan suatu tradisi yang ada di masyarakat itu akan terpengaruh. Maka dari itu, dapat disebutkan bahwa tradisi merupakan bagian dari budaya.

Setiap manusia di setiap daerah yang sudah cukup umur, pasti akan berkeluarga dan menjalani kehidupan rumah tangga. Proses berkeluarga yaitu dengan cara menikah. Dalam penelitian ini yang menjadi fokus kajian adalah salah satu bagian dari upacara pernikahan di Sunda.
Adapun urutan dalam upacara pernikahan di Sunda adalah dimulai dengan sérénsumérén, seserahan, ijab qobul (walimahan), sawér pangantén, bantayan, huap lingkung, dan buka pintu. Fokus kajian dalam penelitian ini adalah tradisi nyawér pangantén.

Nyawér pangantén merupakan salah satu bentuk tradisi lisan kebudayaan masyarakat Sunda. Nyawér pangantén dalam pandangan tradisi lisan merupakan pertunjukan dengan tujuan menyampaikan maksud secara tersembunyi, simbolik, dan dilaksanakan dalam upacara yang sifatnya khusus yaitu dalam upacara pernikahan di tatar Sunda.

Nyawér berasal dari kata sawer. Sawer merupakan lirik (rumpaka) sawer yang biasanya dilagukan atau dinyanyikan dalam nada yang khusus oleh ahlinya dalam upacara nyawer. Jika dilihat dari kontruksi bentuknya, sawer dibentuk oleh puisi yaitu dalam bentuk syair, pupuh, dan sisindiran yang berisi pepatah (Iskandarwassid, 2003, hal.144). Sawer ditulis dalam bentuk puisi. Dalam puisi biasanya terdapat nilai estetika yang ditandai dengan keindahan bahasa yang digunakan, yaitu purwakanti. Menurut Rusyana (dalam Hadish, 1986, hlm. 9), purwakanti dalam sawer ada runtuy pungkas atau "sajak akhir", purwakanti rantayan yaitu dalam satu baris terdapat suara vokal yang diulang ataupun konsonan yang sama, bisa juga suara vokal dan konsonan yang dipadupadankan.

Kegiatan nyawér pangantén dalam upacara adat pernikahan Sunda biasanya dipimpin oleh seorang yang ahli, disebut juga juru sawér. Juru sawér biasanya orang yang mewakili orang tua pengantin dalam memberikan pepatah kepada pengantin dengan cara dilagukan. Biasanya bahasa yang dilagukan oleh juru sawér berupa pepatah orang tua kepada pengantin yang berisi tuntunan dalam berkehidupan rumah tangga. Lirik sawér biasa ditulis dalam bentuk syair, papantunan, dan pupuh. 
Barang-barang yang digunakan dalam tradisi nyawér pangantén di antaranya berupa beras putih, kunyit yang telah diiris tipis, permen atau kembang gula, uang logam yang banyaknya sesuai dengan kemampuan yang menyelenggarakan, dan payung agung yang digunakan untuk memayungi pengantin. Tradisi nyawér pangantén dimulai dengan juru sawér melagukan lirik sawer, setelah itu juru sawer dan orang tua pengantin melemparkan (yang disebut juga nyawér) barang-barang yang digunakan yaitu beras, kunyit, permen dan uang ke arah pengantin dan keluarga besar pengantin yang hadir dalam tradisi nyawér pangantén (Muchtar, 1987, hal. 127-128).

Tradisi nyawér pangantén adalah tradisi lisan yang berkembang di masyarakat Sunda. Tradisi lisan yaitu kebudayaan yang diwariskan melalui kelisanan (oral tradition). Tradisi lisan mencakup unsur kebudayaan masyarakat, di antaranya sistem religi, bahasa, teknologi, ekonomi, seni, organisasi, dan pendidikan. Tradisi lisan juga bisa berupa gagasan-gagasan dan kegiatan. Pada hakikatnya tradisi lisan berupa ekspresi dari kebudayaan masyarakat yang melaksanakannya. Tradisi lisan bisa berwujud bahasa komunikasi sehari-hari, bahasa formal, seni musik, seni tari, teater, upacara dsb. Karena diwariskan secara lisan, biasanya hanya diingat dalam memori manusia saja. Tapi dengan perkembangan zaman sekarang, tradisi lisan dapat didokumentasikan dengan cara saintifik dengan didukung oleh kejadian melalui perspektif multi disiplin ilmu (Takari, 2013, hal. 2).

Tradisi lisan yaitu segala wacana yang diucapkan dan mencakup kelisanan dan keberaksaraan (Irwanto, 2012). Sedangkan menurut Taylor (dalam Yohana, 2015) menyebutkan bahwa tradisi lisan yaitu suatu hal yang diucapkan atau dilisankan secara lisan. Kejadian tradisi lisan dibagi menjadi tiga bagian penting, yaitu kejadian yang berkaitan (1) bentuk tradisi lisan yang mencakup teks, ko-teks, dan konteks, (2) isi dari tradisi lisan yang berkaitan dengan fungsi dan makna, nilai dan norma, dan kearifan lokal, dan (3) revitalisasi juga upaya untuk melestarikan tradisi lisan (Sibarani, 2015).

Dalam tradisi nyawér pangantén terdapat nilai-nilai luhur yang sangat penting dalam kehidupan. Salah satu nilai luhur yang sangat penting dan besar pengaruhnya dalam kehidupan adalah pendidikan. Pendidikan tidak hanya bisa diperoleh dari ilmu sains saja, melainkan pendidikan dari kearifan lokal pun besar pengaruhnya. Hal demikian disebut etnopedagogik.

Istilah "etnopedagogik" berasal dari kata etno dan pedagogik. Istilah etno berasal dari kata etnos, yang dalam bahasa Yunani berarti "generasi bangsa" atau "lokal". Pedagogik yaitu ilmu mengenai pendidikan dan pengajaran (Sudaryat, 2015, hal. 120). Hal ini menjadi dasar atas pendapat Alwasilah (2009, hal. 50) yang menjelaskan bahwa etnopedagogik merupakan praktik pendidikan berbasis kearifan lokal dalam berbagai hal, seperti halnya cara mengobati penyakit, seni bela diri, lingkungan hidup, sistem pertanian, ekonomi, pemerintahan, sistem perbintangan, dsb. Maka dari itu, akan berkembang etnofilosofis, etnopsikologi, etno musikologi, etnopoliti, dll.

Menurut Rustaman (dalam Albaiti, 2015), etnopedagogik yaitu salah satu praktik pendidikan yang didasari kearifan lokal serta bersumber dari nilai-nilai kultural suatu etnis yang menghasilkan standar sikap dan tingkah laku manusia.

Pada hakikatnya pendidikan bertujuan untuk "memanusiakan manusia". Pendidikan bukan hanya transfer ilmu (transfer of knowladge), tetapi lebih jauh dari itu adalah transfer nilai (transfer of value) (Alwasilah, 2009, hal. 40). Menurut Kartadinata (dalam Sudaryat, 2015, hal. 120), proses pendidikan yang dilatarbelakangi oleh budaya lokal itu sangat penting untuk dilaksanakan. Tujuannya agar pendidikan bisa membangun dan mewariskan nilai-nilai 
budaya lokal sebagai jati diri utama atau identitas suatu bangsa.

Dalam penelitian ini, fokus kajiannya adalah tradisi nyawér pangantén. Penelitian tradisi nyawér pangantén akan terungkap jelas dengan menggunakan struktur kajian tradisi lisan. Serta tradisi nyawér pangantén dikaitkan dengan kajian etnopedagogik dan hasil dari bahasannya dijadikan sebagai bahan ajar di SMA. Tujuan dari penelitian ini adalah untuk mengenal lebih jauh dan menambah pengetahuan tentang tradisi nyawér pangantén. Serta untuk mendeskripsikan struktur tradisi nyawér pangantén, mendeskripsikan nilai-nilai etnopedagogik dalam tradisi nyawér pangantén, dan mendeskripsikan tradisi nyawér pangantén bisa digunakan sebagai alternatif bahan ajar bahasan budaya Sunda di SMA.

\section{METODE}

Metode yang digunakan dalam penelitian ini yaitu metode deskriptif dari kejadian tradisi lisan. Metode ini menggambarkan segala hal yang berkaitan dengan kegiatan tradisi lisan di kehidupan masyarakat. Metode deskriptif ini dapat digunakan dengan membahas kompleksitas objek penelitian. Metode deskriptif diharapkan dapat membahas fenomena tradisi lisan dari tradisi nyawér pangantén berdasarkan prespektif pelaku yang terlibat dikaitkan dengan fungsi dalam kehidupan sehari-hari.

Sumber data dalam penelitian ini yaitu tradisi nyawér pangantén yang termasuk ke dalam tradisi lisan. Penelitian tradisi lisan menggunakan data kualitatif berupa informan yang dipilih secara purposive berdasarkan beberapa pertimbangan yang mengacu kepada tujuan penelitian. Informan dipilih dengan pertimbangan berdasar keahlian dalam bidangnya, yaitu seorang juru sawer yang berada di Cikaso Kecamatan Cicadas Kota Bandung, dan juga dokumentasi tradisi nyawér pangantén yang dilaksanakan di Gedung Graha Alif Kecamatan Solokanjeruk Kabupaten Bandung.
Sumber data dalam penelitian ini mencakup data primer dan sekunder. Data primer didapatkan dari hasil wawancara dan observasi. Wawancara dilakukan dengan maksud untuk mendapat pengetahuan, pendapat, dan pengalaman, informan. Observasi di lapangan dilakukan dengan maksud untuk mendapatkan data yang lebih lengkap mengenai kejadian, kegiatan, tingkah laku informan serta interaksi sosial yang lebih lengkap. Data sekunder didapatkan dari telaah pustaka dan pendokumentasian, dengan maksud untuk membantu peneliti jika ada data yang terlewat dan tidak tercatat oleh peneliti. Instrumen yang digunakan dalam penelitian ini meliputi, instrumen wawancara, observasi, dokumentasi, telaah pustaka dan analisis data.

\section{HASIL DAN PEMBAHASAN}

Berdasarkan hasil analisis data, dalam tradisi nyawér pangantén terdapat maknamakna yang luhur bagi kelangsungan hidup. Adapun pembahasannya adalah sebagai berikut.

\section{Struktur Sawér Pangantén}

Struktur dalam tradisi lisan yaitu mencakup teks, ko-teks, dan konteks. Teks berupa hal yang menjadi pusat kegiatan tradisi lisan secara menyeluruh. Ko-teks berupa unsur-unsur yang berkaitan dalam kegiatan tradisi lisan dan membantu untuk melengkapi analsis téks. Serta konteks yaitu kondisi ketika tradisi berlangsung, konteks dalam tradisi lisan bisa berupa konteks situasi, sosial, budaya atau ideologi. Kajian tradisi lisan memiliki formula yang mencakup teks, ko-teks, dan konteks. Maka dari itu, dalam memahami teks bergantung pada pemahaman ko-teks dan konteksnya, juga sebaliknya (Sibarani, 2015).

Pembahasan lebih lanjut mengenai teks, ko-teks, dan konteks dalam tradisi nyawér pangantén adalah sebagai berikut.

1) Teks 
Dalam tradisi nyawér pangantén yang menjadi teks adalah tradisi nyawér pangantén secara keseluruhan.

\section{2) Ko-teks}

Ko-teks dalam tradisi nyawér pangantén mencakup semua unsur-unsur yang terkait dalam tradisi nyawér pangantén, di antaranya pelaku, barangbarang yang digunakan dalam tradisi nyawér pangantén, tata letak pada saat berlangsungnya tradisi nyawér pangantén, dan waktu pelaksanaan tradisi nyawér pangantén. Untuk penjelasan lebih lanjut akan dibahas di bawah ini.

\section{a) Pelaku}

Pelaku yang terlibat aktif dalam kegiatan nyawér pangantén adalah juru sawer, orang tua pengantin, pengantin, payung agung, dan keluarga besar dari kedua pengantin.

b) Barang-barang yang digunakan

Barang-barang yang digunakan dalam tradisi nyawér pangantén di antaranya seperti di bawah ini.

1) Beras, melambangkan kesejahteraan. Dalam kehidupan berkeluarga harus bisa mencari bahan pokok makanan, agar kebutuhan pangan tercukupi. Apabila kebutuhan poko pangan tercukupi, dapat dikatakan kehidupan keluarganya ada dalam taraf kesejahteraan.

2) Kunyit, melambangkan emas yang mempunyai arti kemuliaan untuk pengantin. Selain itu, kunyit juga memiliki arti pepatah untuk pengantin bahwa dalam menjalani kehidupan rumah tangga harus seperti kunyit, dalam bahasa Sunda konéng, namanya konéng warnanya juga konéng (kuning), artinya melambangkan bahwa apa yang ada di dalam hati harus sama dengan perkataan yang diucapkan, intinya suami dan istri itu haruslah saling jujur dalam berucap. Dan juga kunyit merupakan obat yang salah satunya untuk penyakit maag, dari hal tersebut suami dan istri haruslah menjadi obat yang bisa menyembuhkan ketika salah satunya ada dalam kesedihan.

3) Permen atau kembang gula, merupakan makanan yang sangat disukai oleh semua umur, dari mulai anak kecil sampai orang dewasa. Dari hal tersebut melambangkan bahwa kehidupan rumah tangga itu haruslah rukun dan tentram sehingga disukai oleh semua orang yang melihatnya. Selain itu permen juga rasanya manis, jikalau diaplikasikan dalam bahasa Sunda pengantin itu haruslah amis budi, yang artinya murah senyum kepada semua orang. Sehingga banyak orang yang menyukai dan mengasihi.

4) Uang, melambangkan kehidupan dunia. Artinya pepatah orang tua kepada pengantin, harus bisa mencari rezeki untuk memenuhi kebutuhan hidup berkeluarga. Tapi jika sudah ada rezeki jangan melupakan kewajiban untuk memberikan sedekah yang sesuai dengan perintah agama. Utamanya kepada orang tua dan saudara-saudara.

5) Payung, artinya kita harus papayung agung. Yaitu tiada lain harus memiliki iman bahwa kuasa Allah yang menaungi kehidupan kita. Ketika mendapat kebahagiaan ataupun kesedihan dalam kehidupan, kita harus tetap yakin dan berlindung kepada Allah SWT yang telah memayungi kita dalam lindungan-Nya.

\section{c) Tata letak}

Pengantin menghadap rumah yang tepatnya di panyawéran (genting/tempat turunnya air hujan), sedangkan orang tua dan juru sawer di teras rumah. Apabila di dalam gedung, pengantin membelakangi pintu masuk gedung, serta orang tua dan juru sawer ada di depan dan menghadap pengantin. Hal tersebut melambangkan bahwa ketika pengantin sudah berkeluarga akan berpisah dari rumah orang tua. Payung agung di belakang pengantin guna memayungi pengantin. Biasanya yang memegang payung agung adalah seorang laki-laki, sebab jika dilihat dari struktur 
biologisnya laki-laki memiliki tenaga yang lebih kuat dibanding perempuan. Serta hal tersebut melambangkan bahwa laki-laki harus bisa menjadi tempat berteduh yang menenangkan istrinya ketika ada dalam kesedihan. Keluarga dari kedua pengantin ada di belakang pengantin, hal tersebut melambangkan bahwa keluarga besar pengantin ikut mengantarkan pengantin dengan kebahagiaan. Selain itu, ketika melemparkan (disebut juga nyawér) barang-barang dalam nyawér pangantén, dilemparkan ke arah pengantin dan keluarga besar pengantin. Dilihat dari hal tersebut, artiya bahwa pengantin harus bisa memberi sedekah kepada sesama, dan yang diutamakan adalah saudara.

d) Waktu

Dalam urutan upacara adat pernikahan secara keseluruhan, nyawér pangantén dilaksanakan setelah sungkeman dan sebelum bantayan. Dilaksanakan setelah sah menjadi pengantin. Dengan urutan seperti berikut, pertama juru sawer menyiapkan segala sesuatu yang digunakan dalam kegiatan tradisi nyawér pangantén. Lalu setelah semua lengkap, juru sawer menjelaskan maksud dan tujuan dilaksanakannya tradisi nyawér pangantén tersebut. Stelah itu, juru sawer melagukan lirik sawer yang bisa dalam bentuk syair, papantunan, pupuh, ataupun tembang. Setelah selesai melagukan lirik sawer, juru sawer dan orang tua pengantin melemparkan (disebut juga nyawér) barang-barang berupa beras, kunyit, permen, dan uang yang disimpan dalam bokor ke arah pengantin dan keluarga besar kedua pengantin.

e) Rumpaka (lirik) sawér pangantén Bagéa nu panganténan Jalar istri jatukrami Bagéa nu panganténan Jalar istri jatukrami

Nyorang jalan karaharjaan Mangsa hirup rumah tangga Ayeuna cunduk waktuna Nyumponan papagon Gusti
Mugia aya gunana

Pangrajah ieu pépéling

Tuturunan ti karuhun

Pamuka karaharjaan

Jembarna nu Maha Agung

Asih henteu pilih tanding

Kaasup ka hidep duaan

Nu geulis sareng nu kasép

Diijabah panejana

Dumugi tepung rarabi

Rarabi téh gawé luhung

Pancén suci ti Yang Agung

Ulah rék dianggap gampang

Sumawon dianggap ulin

Kamudi sing ati-ati

Bisi cilaka nya diri

Sakitu pamundut sepuh

Regepkeun ku eusi batin

Pamugi mulus rahayu

Bral geura miang

Dirahmat ku Nu Kawasa

Mugi hidep bagja diri

Aamiin Ya Robbal Alamin

Gusti nangtayungan

3) Konteks

Konteks dalam tradisi nyawér pangantén berkaitan dengan fungsi dilaksanakannya nyawér pangantén. Fungsi nyawér pangantén yaitu pepatah orang tua kepada pengantin agar menjadi bekal moral untuk menjalani kehidupan rumah tangga sebagai suami istri.

Selain membahas mengenai struktur tradisi lisan dalam tradisi nyawér pangantén, hasil penelitian dikaitkan dengan ciri-ciri kelisanan. Menurut Ong (dalam Hidayat, 2016), terdapat beberapa ciri yang berkaitan dengan kelisanan yaitu (1) aditif, (2) empatetis-partisipatori, dan (3) homestatik. Serta ciri-ciri kelisanan dalam tradisi nyawér pangantén adalah sebagai berikut.

a) Aditif

Aditif yaitu gaya penuturan disesuaikan dengan penerimanya. Jelas terlihat bahwa dalam tradisi nyawér 
pangantén, juru sawer menyesuaikan dengan keadaan ketika berlangsungnya kegiatan tradisi. Selain menggunakan bahasa Sunda dalam komunikasi ketika berlangsungnya kegiatan tradisi, gaya penuturannya pun disesuaikan dengan isi dari rumpaka sawer yang dilagukan oleh juru sawer ditujukan untuk pengantin yang akan menjalani kehidupan rumah tangga. Isinya pun berupa pepatah untuk pengantin dalam menjalani kehidupan berkeluarga agar pengantin dalam membangun bahtera rumah tangga ada dalam kebahagiaan.

b) Empatetis-partisipatori

Empatetis-partisipatori yaitu belajar atau memahami bahwa masyarakat tradisi lisan harus mempunyai peran aktif yang dicerminkan dengan saling menghormati dan membangun kesadaran bersama. Terlihat jelas bahwa tradisi nyawér pangantén kaya akan nilai-nilai moral. Juru sawer sebagai orang tua pengantin yang memiliki rasa sayang kepada pengantin, diekspresikan dengan cara memperlihatkan rasa sayangnya dengan cara memberikan pepatah dalam menjalani kehidupan rumah tangga. Dalam kegiatan nyawér pangantén, keluarga besar pengantin yang hadir mencerminkan kesadaran bersama dengan memperlihatkan rasa saling menghormati. Hal tersebut terlihat ketika juru sawer melagukan lirik sawer, dan pada saat itu bukan hanya pengantin bahkan semua orang yang hadir sama-sama mendengarkan dan menghayati isi pepatah yang dilagukan juru sawer. Dalam konteks tersebut, dapat diartikan bahwa ketika orang tua menasihati haruslah didengar dan dilaksanakan. Hal tersebut merupakan cerminan manusia yang saling menghormati dan mempunyai moral yang baik, terutama kepada orang tua.

c) Homestatik

Homestatik yaitu masyarakat budaya lisan mempunyai usaha dalam membangun keseimbangan hidup. Masyarakat yang masih melaksanakan tradisi nyawér pangantén tentunya mempunyai tujuan untuk mempertahankan warisan budaya nenek moyang yang kaya akan nilai-nilai luhur dalam keberlangsungan hidup masyarakat. Jika pepatah yang tersirat dalam tradisi nyawér pangantén dilaksanakan hususnya oleh pengantin, umumnya semua orang yang sudah berkeluarga, niscaya akan menciptakan keseimbangan hidup yang dihiasi dengan kebahagiaan.

\section{Nilai Etnopedagogik Tradisi Nyawér Pangantén}

Orientasi etnopedagogik Sunda mencetak manusia yang memiliki karakter dan moral, yaitu manusia yang melaksanakan perintah hukum, seperti hukum agama, hukum negara, dan hukum adat. Maka dari itu, dalam upaya mencapai tujuan itu haruslah mempunyai moral yang baik. Menurut Warnaen (dalam Sudaryat, 2015, hal. 125), ada enam penanda moral kemanusiaan yaitu moral manusia kepada Tuhan, moral manusia kepada pribadinya, moral manusia kepada manusia lainnya, moral manusia kepada alam, moral manusia terhadap waktu, dan moral manusia dalam mencapai kepuasan lahir dan batin. Moral manusia kepada Tuhan menggambarkan sikap dan tingkah laku manusia yang taat dalam melaksanakan ajaran agama, toleransi terhadap agama lain, dan hidup rukun dengan yang beda agama. Moral manusia kepada pribadinya merupakan gambaran sikap manusia kepada dirinya sebagai individu, yang ditandai oleh kualitas sumber daya manusia (SDM) atau sumber daya insani (SDI). Nilai-nilai moral tersebut tergambar dari sifat-sifat seperti sopan, sederhana, jujur, berani, teguh dalam kebenaran, dapat dipercaya, hormat dan menghargai orang lain, berhati-hati, bisa mengendalikan diri, adil serta mempunyai pikiran yang luas, cinta terhadap tanah air dan bangsa, juga baik hati. Moral manusia kepada manusia lainnya merupakan sikap manusia kepada manusia lainnya dalam kehidupan bermasyarakat, bangsa dan negara, yang ditandai dengan kesadaran adanya masyarakat multi religi, multi etnis, dan multikultur. Moral manusia kepada alam 
merupakan sikap manusia kepada lingkungan alam yang ditandai dengan kesadaran ekologi dan kewilayahan. Sikap dan tingkahlaku yang menghindari dan mencegah lingkungan serta bagaimana cara mengatasinya. Moral manusia terhadap waktu merupakan sikap manusia bagaimana memanfaaatkan waktu, yang ditandai dengan kesadaran adanya waktu linear dan cyclis, dan waktu baqa. Serta moral manusia dalam mencapai kepuasan lahir dan batin merupakan sikap manusia dalam memenuhi kebutuhan dan kepuasan lahir dan batin yang ditandai dengan kesadaran etka dan estetika.

Berdasarkan hasil analisis nilai etnopedagogik tradisi nyawér pangantén, ada beberapa temuan yang utamanya dapat digunakan sebagai tuntunan hidup manusia dalam menjalani kehidupan. Adapun bahasan lebih jelasnya adalah sebagai berikut.

Moral-moral manusia kepada Tuhan, tersirat dalam lirik sawér di antaranya ayeuna cunduk waktuna nyumponan papagon Gusti, dari lirik tersebut dijelaskan bahwa ungkapan juru sawer merupakan ucapan untuk mengingatkan kepada semua orang yang hadir dalam tradisi nyawér pangantén bahwa pernikahan itu salah satu perintah Allah yang sesuai dengan apa yang tersurat dalam Al-Quran yaitu "Hai manusia, bertakwalah kepada Allah yang menciptakan engkau dari satu manusia serta menciptakan jodohnya, dan mempunyai keturunan dari keduanya baik laki-laki ataupun perempuan, dan bertaqwalah kepada Allah..." QS. An Nisa ayat 1 .

Dalam lirik selanjutnya yaitu $n u$ geulis sareng nu kasép, diijabah panejana, dumugi tepung rarabi, maksudnya adalah hal ini sudah merupakan ketentuan Allah, bahwa yang menjadi pengantin laki-laki sudah ada guratan takdir berjodoh dengan pengantin perempuan. Sesuai dengan keterangan yang sesuai dengan QS. Adz Dzariyat ayat 49 yang artinya "Dan segala sesuatu telah Kami jadikan berpasangan, agar kamu mengingat kuasa Allah". Hal tersebut merupakan perintah Allah bahwa manusia haruslah senantiasa mengingat Allah, bahwa segala hal yang terjadi di muka bumi ini adalah kehendak-Nya. Jelas bahwa dalam kegiatan tradisi nyawér pangantén banyak hal-hal yang didasari atas iman kepada Allah SWT. Dengan demikian, gambaran moral manusia kepada Tuhan dalam tradisi nyawér pangantén terlihat dalam esensi lirik sawer yang sebagiannya merupakan do'a yang dipanjatkan kepada Allah SWT. Maka dari itu masyarakat tradisi masih berpegang teguh atas keyakinan kepada Allah, bahwa segala sesuatu yang mengkehendaki adalah Allah SWT.

Moral manusia kepada pribadinya, digambarkan dari isi pepatah yang disampaikan oleh juru sawer. Adapun sebabnya pengantin diberikan pepatah oleh juru sawer yaitu agar pengantin menjalani kehidupan berkeluarga ada dalam kesejahteraan dengan berperilaku terhadap suami atau istrinya sesuai dengan isi pepatah yang diucapkan juru sawer. Keduanya harus saling menyayangi dan mencintai, jangan mengedepankan ego masing-masing, tapi haruslah keduanya saling bisa mengontrol diri dan mengerti akan pasangan hidupnya. Seperti apa yang dijelaskan dalam hadits yaitu "Sesungguhnya dunia itu adalah perhiasan dan perhiasan yang sebaik-baiknya adalah istri yang sholehah" (HR. Muslim). Jelas bahwa dalam kehidupan berkeluarga yang diharapkan dan yang diperintahkan itu menjadi manusia yang mempunyai moral yang luhur yang dicerminkan dalam manusia yang sholeh dan sholehah serta saling memahami dan menyayangi terhadap pasangannya. Terutama suami harus bisa menjadi pemimpin dalam menjalani bahtera rumah tangga dan menjadi tempat berlindung bagi istri yang sedang mengalami kesedihan, sebaliknya istri harus menuruti dan taat kepada suaminya. Hal demikian merupakan cerminan moral manusia yang baik terhadap pribadinya dalam kehidupan berkeluarga. 
Moral manusia kepada manusia lainnya, dapat digambarkan dalam hal dimana juru sawer mempunyai rasa peduli dan sayang terhadap pengantin sebagai anaknya dengan cara memberikan bekal moral yang terbungkus dalam pepatahnya agar pengantin ada dalam kehidupan yang sejahtera. Hal tersebut tercantum dalam QS. Al Hujurat ayat 10 yang artinya "Orang-orang yang beriman itu adalah bersaudara. Oleh karena itu damaikan (perbaiki hubungan) antara kedua saudara itu dan takutlah kepda Allah, agar kamu mendapat rahmat". Serta diterangkan pula dalam HR. Bukhari dan Muslim, "Tidak sempurna iman seseorang di antara kamu hingga dirinya mencintai (kebaikan) untuk saudara-saudaranya merupakan suatu hal yang sangat dicintai untuk dirinya". Maka dari itu, mannusia harus memiliki moral yang baik kepada saudaranya. Seperti halnya yang digambarkan juru sawer yang memiliki kepedulian dan rasa sayang kepada pengantin.

Moral manusia kepada alam, digambarkan dengan cara menggunakan barang-barang hasil bumi dalam kegiatan nyawér pangantén. Barang-barang tersebut adalah beras dan kunyit. Alasan orang tua menggunakan barang-barang hasil bumi tersebut dengan penganalogian sebagai hal yang mempunyai makna yang luhur dalam kehidupan manusia, tiada lain untuk menghargai dan senantiasa manusia bersyukur kepada Yang Maha Mencipta yaitu Allah SWT. Sebagaimana yang telah disebutkan dalam QS. An Naba ayat 14-16, "Dan Aku turunkan dari awan, air yang turun deras, untuk Aku tumbuhkan dengan air itu biji-bijian dan tumbuhan, serta kebun-kebun yang subur". Dengan demikian manusia haruslah menjaga hasil bumi yang besar manfaatnya bagi kehidupan, dan haruslah tetap bersyukur kepada Alloh SWT yang telah menciptakannya.

Moral manusia terhadap waktu, dijelaskan dalam hadits yang berbunyi "Gunakan lima perkara sebelum datang yang lima; waktu muda sebelum datang waktu tua, waktu sehat sebelum datang waktu sakit, waktu kaya sebelum datang waktu miskin, waktu senggang sebelum datang waktu sibuk, dan waktu hidup sebelum datang waktu mati" (HR. Hakim disohehkan oleh Al Albani). Jelas bahwa manusia mempunyai pertimbangan dalam memutuskan suatu perkara. Sebelum datang perkara yang tidak diharapkan dalam kehidupan rumah tangga yang sifatnya tidak baik, maka dari itu juru sawer sebagai orang tua memberikan pepatah kepada pengantin agar pengantin kelak dalam membangun kehidupan berkeluarga ada dalam kesejahteraan.

Moral manusia dalam mencapai kepuasan lahir dan batin, digambarkan dalam perilaku juru sawer dalam memberikan pepatah kepada pengantin. Hal tersebut adalah salah satu hal yang merupakan kebaikan. Dijelaskan dalam QS. $\mathrm{Al}$ Ankabut ayat 7 yang artinya "dan orangorang yang beriman yang beramal sholeh, benar-benar akan Aku hapus dari dosa-dosa mereka dan benar-benar akan Aku beri pahala yang lebih dari apa yang mereka kerjakan". Jelas bahwa jika orang tua yang memberikan pepatah serta dibarengi dengan keimanan, dan juga pengantin mengerjakan apa isi dari pepatah itu, maka suatu kebaikan telah dikerjakan keduanya. Bukan hanya kebahagian lahir yang didapatkan, tapi kebahagiaan batin pun terpuaskan. Bukan hanya kebahagiaan dunia yang didapatkan, kebahagiaan kelak diakhirat pun pasti akan didapatkan.

Tradisi nyawér pangantén mempunyai nilai-nilai yang luhur, selain dari memberikan pepatah, juga merupakan sarana untuk melakukan kebaikan lainnya yaitu bersedekah dari sebagian hartanya. Seperti halnya dijelaskan dalam keterangan yaitu "Hey anak Adam, berinfaklah kalian (nafkahkan harta kalian), sesungguhnya Aku akan memberi nafkah kepada kalian" (HR. Muslim). Jelas bahwa sedekah bukan menjadikan orang menjadi miskin, tapi sedekah merupakan sarana untuk yang melaksanakannya mendapat rezeki yang lebih banyak lagi. Tentunya orang yang 
menjalakan hal tersebut akan mendapat kepuasan lahir dan batin.

Serta dalam keterangan yang lainnya dijelaskan bahwa "Sesungguhnya, jika suami menatap istrinya (dengan kasih sayang) dan istrinya juga menatap suaminya (dengan kasih dan sayang pula), Allah akan menatap keduanya dengan kasih dan sayang. Serta jika suami menggenggam jemari istrinya (dengan kasih dan sayang) niscaya akan gugur semua dosa-dosa dari jemari-jemari mereka" (HR. Abu Sa'id). Jelas terlihat dalam keterangan tersebut, bahwa kebahagiaan lahir dan batin dapat didapatkan oleh pengantin jika perilaku dalam kehidupan berkeluarga sesuai dengan perintah agama.

Ketika semua hal tersebut dilaksanakan dalam kehidupan, maka akan menjadi manusia yang mempunyai karakter yang baik. Kebaikan yang dikerjakan yaitu suka memberi, mempunyai akhlak yang baik, dsb. Maka dari itu kebahagian lahir batin niscaya akan didapat.

\section{Bahasan Alternatif Bahan Ajar}

Agar kegiatan pembelajaran berlangsung sesuai dengan tujuan pembelajaran, guru haruslah memilih bahan ajar yang baik. Jika dalam memilih bahan ajar tidak sesuai dengan kurikulum dan kompetensi yang harus dicapai oleh siswa, tentunya proses pembelajaran tidak akan berlangsung dengan baik. Dengan demikian, menurut Nasution (dalam Haerudin, 2013, hal. 77) ada beberapa hal yang harus diperhatikan dalam memilih bahan ajar yaitu sebagai berikut.

a) Tujuan yang ingin dicapai.

b) Dianggap mempunyai nilai penting bagi kehidupan manusia.

c) Dianggap memiliki nilai warisan nenek moyang.

d) Bermanfaat untuk menguasai suatu keilmuan.

e) Sesuai dengan kebutuhan dan minat siswa.

Bahasan tradisi nyawér pangantén dapat dijadikan bahan ajar di SMA yang sesuai dengan KIKD pembelajaran bahasa
Sunda, sebab sudah memenuhi kriteria pemilihan bahan ajar, seperti halnya di bawah ini.

a) Tujuan yang ingin dicapai.

Pembelajaran bahasa Sunda bertujuan agar siswa sebagai generasi muda tidak melupakan warisan nenek moyang, baik bahasa, seni, dan budayanya. Tradisi nyawér pangantén merupakan warisan budaya yang kaya akan nilai moral kemanusiaan. Salah satu tujuan pembelajarannya adalah agar siswa mengenal dan mempunyai moral-moral kemanusiaan yang dicerminkan dalam tradisi nyawér pangantén dan juga di samping itu siswa tetap mengenal dan menggunakan bahasa daerahnya yaitu bahasa Sunda.

b) Dianggap mempunyai nilai penting bagi kehidupan manusia.

Sebab bahasan tradisi nyawér pangantén diaplikasikan dalam bahan ajar yaitu salah satunya mempunyai nilai-nilai yang luhur dalam kelangsungan hidup di masyarakat. Dalam tradisi nyawér pangantén tersirat nilai-nilai moral manusia yang luhur, seperti mempunyai keyakinan bahwa Allah yang telah mengatur alam semesta dan seisinya, berakhlak baik kepada semua orang, bersedekah, dsb.

c) Dianggap memiliki nilai warisan nenek moyang.

Tradisi nyawér pangantén merupakan hal yang biasa dilaksanakan ketika seseorang telah cukup umur untuk berkeluarga, yaitu dalam upacara perkawinan. Dengan diaplikasikan menjadi bahan ajar di sekolah, salah satu hal yang positifnya adalah dapat menjadi sarana transmisi budaya nenek moyangnya terdahulu. Dengan dijadikan bahan ajar di sekolah, tentunya semua siswa yang menerima pembelajaran tersebut dapat mengenal dan memahami lebih jauh salah satu warisan budaya nenek moyangnya.

d) Bermanfaat untuk menguasai suatu keilmuan.

Tentunya bahasan tentang tradisi nyawér pangantén merupakan bahasan budaya. Jika disajikan dalam materi 
pembelajaran, tujuan yang diharapkan adalah siswa memiliki pengetahuan dalam bidang kebudayaan. Dengan cara memahami isi dan makna yang tersirat dalam tradisi nyawér pangantén, siswa mempunyai pengetahuan bahwa setiap kegiatan yang termasuk dalam kebudayaan itu semua unsur-unsurnya memiliki arti yang sangat luhur bagi kehidupan manusia. Dengan demikian, bahasan dari tradisi nyawér pangantén menjadi stimulus untuk siswa dalam menganalisis lebih jauh lagi tentang fungsi dan makna dalam budaya yang lainnya.

e) Sesuai dengan kebutuhan dan minat siswa.

Jika melihat fenomena zaman sekarang utamanya di kalangan generasi muda, minat siswa dalam mencintai budaya tradisional sangat minim. Hal tersebut disebabkan oleh kehidupan yang lebih maju, teknologi yang lebih canggih, akhirnya budaya yang sifatnya tradisional minim perhatian. Padahal dalam kebudayaan tradisional banyak mengandung nila-nilai yang luhur dalam kehidupan. Nilai-nilai yang luhur itu yang sebenarnya menjadi kebutuhan bagi siswa sebagai generasi bangsa, sebab dengan memahami makna yang terkandung dalam nilai-nilai tersebut menjadi modal utama untuk mengembangkan karakter dalam diri siswa dalam menyongsong kehidupan yang akan dijalaninya.

Hasil analisis tradisi nyawér pangantén dapat digunakan sebagai bahan ajar di SMA/SMK/MA. Sebab hasil analisis dari tradisi nyawér pangantén dapat ditulis menjadi materi bahasan budaya Sunda. Pembelajaran mengenai bahasan budaya Sunda tercantum dalam kurikulum yang disusun dalam Kurikulum Tingkat Daerah yang ditetapkan oleh pemerintah daerah Jawa Barat. Dengan KIKD sebagai berikut, 11.1.1 Mensyukuri anugerah Tuhan akan keberadaan bahasa Sunda dan menggunakannnya sesuai dengan kaidah dan konteks sosial budaya sebagai sarana komunikasi melalui rumpaka kawih, sajak, mantra, novel, bahasan, deskripsi, warta, dan wawancara. 11.2.2 Menunjukan perilaku jujur, disiplin, peduli, dan santun dalam berbahasa Sunda untuk memahami teks bahasan budaya sunda dan deskripsi yang mengandung pakeman basa. 11.3.5 Mengidentifikasi dan menganalisis bahasan budaya Sunda sesuai dengan kaidah-kaidahnya.11.4.5 Menyusun dan menanggapi bahasan tentang Budaya Sunda sesuai dengan kaidah-kaidahnya. (Disdik Provinsi Jawa Barat, 2013, kc. 14).

Dengan digunakan menjadi bahan ajar di SMA dalam bentuk teks bahasan budaya, dapat menambah wawasan siswa lebih luas lagi mengenai budaya Sunda. Dengan dibahas secara lebih detail mengenai unsur-unsur yang tersirat dalam tradisi nyawér pangantén, dapat menjadi cerminan untuk siswa yang akhirnya diharapkan siswa dapat membangun karakteristik jati diri urang Sunda yang mempunyai moral sebagai manusia yang berbudi pekerti.

\section{SIMPULAN}

Dalam pembahasan di atas, dapat disimpulkan bahwa struktur tradisi nyawér pangantén dalam kajian tradisi lisan adalah teks yaitu tradisi nyawér pangantén; koteks yaitu pelaku (juru sawer, orang tua, pengantin, payung agung, dan keluarga besar pengantin), barang (beras, kunyit, permen, uang, payung), tata letak, waktu, dan rumpaka; konteks yaitu pepatah orang tua kepada pengantin agar menjadi bekal moral untuk menjalani kehidupan rumah tangga.

Tradisi nyawér pangantén mempunyai nilai-nilai yang sangat luhur bagi kehidupn manusia. Sebab dalam tradisi nyawér pangantén terdapat nilai moral kemanusiaan yang sangat luhur, yaitu moral manusia kepada Tuhan, moral manusia kepada pribadinya, moral manusia kepada manusia lainnya, moral manusia kepada alam, moral manusia terhadap waktu, dan moral manusia dalam mencapai kepuasan lahir dan batin. 
Bahasan tradisi nyawér pangantén dapat dijadikan sebgai bahan ajar dalam materi bahasan budaya Sunda di SMA. Sebab bahasan tradisi nyawér pangantén memenuhi kriteria dalam memilih bahan ajar. Di samping itu, dalam tradisi nyawér pangantén juga tersirat nilai-nilai yang sangat penting untuk kehidupan generasi bangsa kedepannya, serta bisa menjadi stimulus untuk siswa dalam membangun dan mengembangkan karakter siswa yang jauh lebih baik lagi.

\section{PUSTAKA RUJUKAN}

Albaiti. (2015). Kajian Kearifan Lokal Kelompok Budaya Dani Lembah Baliem Wamena Papua. Jurnal Pendidikan Nusantara Indonesia, 1 (1)

Alwasilah, C.A., Suryadi K., \& Karyono, T. (2009). Etnopedagogik. Bandung: Kiblat

Al-Quran dan Hadits [Online]. Diakses dari https://apwa.wordpress.com/perpustaka an/dalil-nikah/

Disdik Provinsi Jawa Barat. (2013). Kurikulum Tingkat Daerah Mata Pelajaran Bahasa dan Sastra Sunda Berbasis Kurikulum 2013. Bandung: Disdik Provinsi Jawa Barat

Irwanto, D. (2012). Kendala dan Alternatif Penggunaan Tradisi Lisan dalam Penulisan Sejarah Lokal di Sumatera Selatan. Jurnal Forum Sosial, 2 (5)

Iskandarwassid. (2003). Kamus Istilah Sastra. Bandung: Geger Sunten

Hadish, Y. K., spk. (1986). Puisi Sawer Bahasa Sunda. Jakarta: Pusat Pembinaan dan Pengembangan Bahasa Departemen Pendidikan dan Kebudayaan

Haerudin, D. (2013). Panganteur Telaah Buku Ajar. Bandung: JPBD FPBS UPI
Hidayat, M. F. (2016). Peranan Tradisi Lisan dalam Upaya Pelestarian Lingkungan; Studi Ekologi Budaya Goa Ngerong Rengel Tuban. Prosiding Seminar Nasional Kerjasama Prodi Pendidikan Biologi FKIP daengan Pusat Studi Lingkungan dan Kependudukan (PSLK) Universitas Muhamadiyah Malang

Muchtar, Uton dan Ki Umbara. (1987). Modana. Bandung: PT Mangle Panglipur

Lubis, H.N dkk. (2011). Sejarah Kebudayaan Sunda. Bandung: Yayasan Masarakat Sejarawan Indonesia

Rekha, R.D. (2014). Tradisi Babarit Désa di Kecamatan Palasah Kabupatén Majaléngka (Ulikan StrukturalSémiotik). Tesis, Sekolah Pasca Sarjana Universitas Pendidikan Indonesia, Bandung

Sibarani, R. (2015). Pendekatan Antropolinguisstik terhadap Kajian Tradisi Lisan. Retorika: Jurnal Ilmu Bahasa, 1 (1)

Sudaryat, Y. (2015). Wawasan Kasundaan. Bandung: JPBD UPI Bandung

Takari, M. (2013). Tradisi Lisan di Alam Melayu: Arah dan Pewarisannya. Pascasarjana Linguistik Fakultas Ilmu Budaya Universitas Sumatera Utara

Yohana, N. (2015). Kaidah Interaksi Komunikasi Tradisi Lisan Basiacuang dalam Adat Perkawinan Melayu Kampar Riau. Jurnal Penelitian Komunikasi, 1 (18)

\section{UCAPAN TERIMA KASIH}

Terima kasih penulis sampaikan kepada semua pihak yang telah membantu penelitian ini, terutama kepada Penyunting Jurnal Lokabasa atas dimuatnya tulisan ini. 